Artigos

Volume 11 - $2021 \mid$ n. 15

\title{
Recursos Federais para a Educação Básica: pacto federativo e os municípios
}

\author{
Antônio Cláudio Andrade dos Reis \\ Vera Lúcia Jacob Chaves \\ Universidade Federal do Pará (UFPA), Belém/PA - Brasil
}

\section{Resumo}

$\mathrm{O}$ artigo analisa a magnitude dos recursos federais geridos pelo Fundo Nacional de Desenvolvimento da Educação (FNDE), destinados à rede municipal de ensino, identificando o sentido da descentralização das ações do governo central no processo de interação entre os entes federados, com destaque para a rede municipal de ensino. Utilizou-se a metodologia quanti-qualitativa com base em dados documentais e estatísticos. Constatou-se que a redução dos gastos públicos via descentralização esconde o fato do não cumprimento do papel redistribuidor da União, sobrecarregando os demais entes federados, que devem racionar seus recursos, aumentar o número de matrículas nas escolas, sobretudo municipais, sem o devido aumento do aporte financeiro.

Palavras-chave: Política Educacional. Descentralização. Financiamento da Educação Básica. FNDE.

\section{Federal Resources for Basic Education: federative pact and the cities}

\section{Abstract}

The article analyzes the magnitude of federal resources managed by the National Fund for Education Development (FNDE) for the municipal education system, identifying the sense of decentralization of central government actions in the process of interaction between federated entities, with emphasis on municipal education network. A quantitative-qualitative methodology was used based on documentary and statistical data. It was found that the reduction in public spending through decentralization hides the fact that the Union's redistributive role was not fulfilled, overloading the other federated entities, which must ration their resources, increase the number of enrollments in schools, especially municipal ones, without the appropriate increase in financial support.

Keywords: Educational Politics. Decentralization. Financing of Basic Education. FNDE. 
Recursos Federais para a Educação Básica

\section{Introdução}

Este trabalho apresenta resultado de pesquisa realizada com a finalidade de investigar os recursos públicos da educação básica, suas formas de controle e intervenção. Tem como objetivo analisar a magnitude dos recursos federais geridos pelo Fundo Nacional de Desenvolvimento da Educação (FNDE), destinados à rede municipal de ensino, identificando o sentido da descentralização das ações do governo central no processo de interação entre os entes federados, em especial com a rede municipal de ensino.

Os procedimentos metodológicos adotados para o desenvolvimento da pesquisa, de natureza quanti-qualitativa, tiveram as seguintes etapas interligadas: levantamento e análise de estudos relacionados à temática, de documentos afins, além da coleta e tratamento de dados estatísticos provenientes de sites oficiais do governo federal, Secretaria do Tesouro Nacional (STN/FINBRA), relativos ao período de 2003 e 2016.

$\mathrm{O}$ artigo está organizado em três partes distintas. Inicialmente se apresenta uma breve discussão sobre a estratégia neoliberal para desconstruir a escola pública sob o rótulo da sua ineficiência e a defesa que se adéque às novas formas de gestão. Os avanços no quadro educacional, segundo essa visão, residem na implementação de mecanismos de mercado, visando à competitividade e o lucro, incentivando a privatização da educação brasileira.

Em seguida, faz-se uma breve discussão sobre a descentralização enquanto modelo de aplicação de recursos financeiros, com base na literatura produzida sobre o tema. As interferências de políticas governamentais formatam essa descentralização de acordo com seus interesses e, dessa forma, os mecanismos utilizados são inerentes a essas influências. Privatizar as relações sociais dentro dos sistemas educacionais e torná-las mercadorias é a intenção latente da política neoliberal que construiu uma forma de descentralização associada à centralização gerencial, galgada em avaliações e currículos padronizados.

Por fim, trata-se da análise sobre os fluxos de recursos públicos e as relações políticas que se formam entre os entes federados, sobretudo em relação à divisão das receitas tributárias e encargos públicos. Na ótica de participação dos entes federados, observa-se, na arrecadação tributária total, uma tendência de redução na participação da União, enquanto estados e municípios registram aumentos sucessivos nos últimos anos.

\section{Política Neoliberal: efeitos na educação básica pública}

O sistema educacional vigente, na atual e frágil democracia brasileira, ocupa um lugar importante na estratégia da política neoliberal de conquista hegemônica, enquanto campo possível na implementação de regulação e controle social pelos governos. A política neoliberal no Brasil é parte de um processo macro, que se desenvolve internacionalmente, e que tem influenciado reformas nos sistemas educacionais em âmbito mundial.

[...] se quisermos compreender as estratégias que o projeto neoliberal no Brasil tem reservadas para a educação, é importante também compreender que esse processo é parte de um processo internacional mais amplo. Numa era de globalização e de internacionalização, esses projetos nacionais não podem ser compreendidos fora de uma dinâmica internacional (SILVA, 2000, p. 14).

A implementação de políticas neoliberais para a educação vem sendo proposta desde os tempos de Reagan e Thatcher e, segundo Silva (2000), baseiam-se na premissa de que o 
Recursos Federais para a Educação Básica

problema da educação institucionalizada se deve essencialmente a uma má administração e não à falta de recursos. Nessa concepção, o sistema educacional público brasileiro seria, portanto, "improdutivo", ineficiente quanto ao ensino, por apresentar altas taxas de reprovação e evasão.

Frigotto (2010, p. 177) afirma que se vem formando, no senso comum, a ideia de que os problemas da educação e da saúde se devem a um mau gerenciamento e à falta de acompanhamento e avaliação pelo Estado. É o ideário neoliberal ou neoconservador vulgarizando a ideia de que o Estado, a esfera pública, é pesado e inoperante.

Para os neoliberais, a ineficiência acontece devido à incapacidade da escola pública se adequar às novas formas de gestão; à desqualificação dos docentes para exercer sua função e às organizações de classes, que são corporativistas e não buscam mudanças além das questões salariais (BRASIL, 2006). Esses são os motivos que rotulam as escolas públicas como ineficientes naquilo que lhe é básico, ou seja, ensinar e preparar o aluno de forma crítica e criativa para que possa exercer seus direitos como cidadão.

A solução posta pela política neoliberal tem como centralidade a adoção dos mecanismos de mercado e o estímulo à competitividade, que agiriam para tornar a administração mais eficiente e, dessa forma, gerar um produto educacional de melhor qualidade.

[...] a solução, segundo o neoliberalismo, estaria na condução de uma reforma administrativa para tornar a escola eficiente, competitiva e capaz de formar profissionais qualificados para o mercado de trabalho. Para isso, o Estado necessita estabelecer mecanismos de controle e avaliação dos serviços educacionais que devem estar articulados e subordinados às necessidades desse mercado de trabalho (BRASIL, 2006, p. 37).

O que deve sair da escola, portanto, é um "produto" de melhor qualidade para atender diretamente aos interesses do mercado. Por isso, ao condenar-se a escola atual de improdutiva e ineficiente, não se faz pensando nas pessoas e nos grupos sociais envolvidos, sobretudo aqueles que mais sofrem com as desigualdades existentes, "mas [consideram] as necessidades de competitividade e lucro das empresas" (SILVA, 1996, p. 25). O esquema básico então é o de privatizar e preparar os jovens para atuar no mercado de forma empreendedora e competitiva.

Essa política atinge, sobretudo, as crianças e jovens de classes menos favorecidas. Por outro lado, "[...] as classes com poder e recursos continuarão a lutar por pedagogias e currículos que garantam seu investimento em capital cultural e sua posição na estrutura econômica e social" (SILVA, 2000, p. 25).

A ideologia neoliberal que fundamenta as reformas empreendidas nos sistemas educacionais no Brasil, desde o início da década de 1990, postula como necessário um tratamento específico ao sistema educacional. Para tal, os poderes públicos devem transferir ou dividir suas responsabilidades administrativas com o setor privado, admitindo ser um meio de estimular a competição e o aquecimento do mercado, mantendo-se o padrão de qualidade na oferta dos serviços (AZEVEDO, 2004).

Hayek (1983), em seus argumentos baseados em fatores éticos e morais, admite ser de extremo perigo colocar nas mãos do governo um sistema educacional altamente centralizado e de dominação única, uma vez que 
Recursos Federais para a Educação Básica

\begin{abstract}
Quanto mais consciente estivermos do poder que a educação pode exercer sobre a mente humana, mais convencidos devemos estar do perigo de entregar esse poder a uma única autoridade. Hoje, mais do que nunca, não só é indefensável a ideia de que o governo deve administrar as escolas como também não mais se justifica a maioria dos argumentos antes apresentados em seu favor. [...] não é mais necessário que a educação seja não só financiada, mas também ministrada pelo governo (HAYEK, 1983, p. 450).
\end{abstract}

Essa ideologia, favorável a uma descentralização radical, culminaria em uma desresponsabilização do Estado para com a educação, pondo em xeque as suas responsabilidades enquanto financiador da educação nacional, e admite, abertamente, que a política educacional, e qualquer outra política social, só será bem-sucedida se deixar-se levar pelos ditames e leis que regem os mercados, isto é, um controle essencialmente privado.

$\mathrm{Na}$ crise estrutural do capitalismo ${ }^{1}$, cujos reflexos incidem diretamente no frágil parque produtivo nacional e muito seriamente nas conquistas históricas dos trabalhadores, que têm seus direitos reduzidos, o Estado mínimo e o máximo de privatizações em setores essenciais, como previdência, educação e saúde, são elementos centrais da atual conjuntura brasileira. Somado a isto, conecta-se a crise educacional, que, para os neoliberais, é fruto da falta de eficiência, eficácia e produtividade. Gentili (1996, p. 17) afirma que, na perspectiva neoliberal, "[...] os sistemas educacionais contemporâneos não enfrentam [...] uma crise de democratização, mas uma crise gerencial. Essa crise promove, em determinados contextos, certos mecanismos de 'iniquidade' escolar, tais como evasão, a repetência, o analfabetismo funcional, etc.".

Em observância ao fato exposto, fica evidente que há um objetivo político que busca realizar na escola uma profunda reforma administrativa, uma reforma de abrangência macro, capaz de transformar o próprio sistema escolar com a introdução de mecanismos de regulação e de controle focados na eficiência, na produtividade, na eficácia da escola, traduzido no que eles consideram como qualidade educacional.

A aceitação desses preceitos levou à consolidação de reformas educacionais em diversos países da Europa e no Brasil, na década de 1990. Algumas alterações começaram a ser processadas no Brasil em nível dos municípios. Nessa perspectiva, os municípios ganharam certa autonomia pedagógica e financeira no campo educacional, com a aprovação da Constituição Federal de 1988. A prefeitura e a comunidade passaram a ser corresponsáveis pelo processo educacional e a escola sofreu modificações em sua organização pedagógica e administrativa, dentre as quais: a introdução da gestão democrática e de conselhos escolares (envolvendo a participação da comunidade), a elaboração do próprio projeto político-pedagógico, a adequação do currículo e do calendário escolar às necessidades específicas da localidade.

O modelo de tal projeto político para a educação desloca as responsabilidades na execução das políticas para o âmbito local (municípios e escolas), no entanto, as decisões mais importantes são tomadas na esfera federal, de forma centralizada. Nesse modelo, cabe

1 "A crise estrutural se diferencia de toda e qualquer crise cíclica vivenciada no decorrer da história do capitalismo. Uma crise endêmica, cumulativa e permanente que atinge a totalidade da vida social em todas as suas relações e partes constitutivas com a tendência de destruição global" (MÉSZÁROS, 2011). 
Recursos Federais para a Educação Básica

aos municípios e às unidades escolares apenas a execução de propostas curriculares, programas e ações, decididos em âmbito do governo central.

A municipalização dos serviços educacionais mantém a centralização do poder decisório no âmbito da União, portanto, permanece a distância entre as políticas executadas pelos governos federal e estaduais em relação aos municípios, que não levam em consideração suas próprias políticas, suas prioridades e especificidades locais. Por isso se diz que a municipalização se transformou em um processo de "prefeiturização"2. As ações e as responsabilidades para com o ensino foram descentralizadas, ficando a cargo da prefeitura, mas os recursos e a definição de políticas educacionais continuaram centralizados, sob o controle do governo federal.

A situação atual da educação básica no Brasil, suas mazelas e contradições, é reflexo da política neoliberal e neoconservadora imposta à sociedade brasileira, com maior ênfase a partir do governo de Fernando Henrique Cardoso (1995-2002). A política neoliberal esconde que é na própria configuração de mercado que se encontram as raízes da exclusão e da desigualdade social (GENTILI, 1996). Para os neoliberais, a ocorrência da desigualdade é tida como positiva, uma vez que a concorrência deve objetivar o que é melhor e/ou mais capaz, deixando à margem os "incapazes".

[...] os governos neoliberais deixaram (e estão deixando) nossos países muito mais pobres, mais excludentes, mais desiguais. Incrementaram (e estão incrementando) a discriminação social, racial e sexual, reproduzindo os privilégios das minorias. Exacerbaram (e estão exacerbando) o individualismo e a competição selvagem, quebrando assim os laços de solidariedade coletiva e intensificando um processo antidemocrático de seleção 'natural' onde os 'melhores' triunfam e os piores perdem. E, em nossas sociedades dualizadas, os 'melhores' acabam sendo sempre as elites que monopolizam o poder político, econômico e cultural, e os 'piores', as grandes maiorias submetidas a um aumento brutal das condições de pobreza e a uma violência repressiva que nega não apenas os direitos sociais, mas, principalmente, o mais elementar direito à vida (GENTILI, 1996, p. 41-42).

Os efeitos estruturais produzidos pela política neoliberal têm aumentado demasiadamente a pobreza, sobretudo quando considerados os fatores da desigualdade, quais sejam, a injustiça na distribuição de renda, a precariedade do capital social e a exclusão de direitos sociais.

A política neoliberal, ao opor-se à intervenção redistributiva e supletiva do Estado, garante a perpetuidade da desigualdade, facilitando, inclusive, o seu próprio desenvolvimento. Um dos critérios estabelecidos pelo arcabouço neoliberal é de que somente o mercado possui o direito de alocar eficientemente os recursos e fixar os níveis de renda. Tal pensamento deixa à margem todos os esforços no sentido de alcançar a justiça social por meio de uma estrutura balizada de impostos, e, portanto, uma reforma tributária e uma administração do recurso público que atenda os direitos básicos de saúde, educação, habitação e alimentação aos menos favorecidos.

A União, quando sinaliza a organização do sistema nacional de ensino, alude que exercerá função supletiva e redistributiva dos recursos financeiros (CF/88 Art. 211, $\left.\S 1^{\circ}\right)$,

2 Souza e Faria (2004, p. 931) consideram a prefeiturização como "a mera transferência de atribuições somente no plano da administração". A municipalização possui maior amplitude, agrega um número maior de agentes e a comunidade, enquanto que a prefeiturização diz respeito à centralização do poder no Executivo municipal. 
Recursos Federais para a Educação Básica

visando garantir equalização de oportunidades educacionais e padrão mínimo de qualidade do ensino, mediante assistência técnica e financeira aos estados, ao Distrito Federal e aos municípios.

A função redistributiva e supletiva da União, no entanto, não tem como finalidade a redução das desigualdades, especialmente as existentes em matéria educacional, o que confirma o interesse neoliberal quando se considera o estado mínimo brasileiro. Nesse sentido, a realidade econômico-social que se está produzindo no Brasil admite uma das teses básicas da doutrina neoliberal de Hayek, que defende a desigualdade como fundamental para a eficiência e produtividade capitalista (FRIGOTTO, 2010).

O Brasil é desigual. As possibilidades de alcance de direitos igualitários não existem. A forma como se estruturou a política neoliberal atinge todos os aparatos institucionais, tornando relevante a reestruturação por meio de um conjunto de contrarreformas que visem ao ajuste fiscal. Para tanto, é necessário reduzir o papel do Estado como financiador das políticas sociais, descentralizando as responsabilidades fiscais para os outros entes federados, mas mantendo o controle na sua definição. O pacto federativo, estabelecido na Constituição Federal de 1988, na prática nunca foi efetivado concretamente, sobretudo no que se refere à educação.

Os avanços das políticas neoliberais nas últimas décadas refletem estágios diferenciados da descentralização da educação básica efetivada no Brasil, e esconde o papel redistribuidor da União, que admite equidade nos recursos, mas sobrecarrega os entes federados no financiamento educacional.

\section{Descentralização e Financiamento da Educação Básica no Brasil}

Os princípios da descentralização das ações efetivas do Estado, no tocante à educação, estão presentes no Brasil desde a década de 1990, mostrando-se persistente na sua forma hegemônica de lapidar direitos sociais. A descentralização acontece quando se transfere o poder de decisão e autoridade, objetivando o fortalecimento da escola e o devido controle das atividades da educação pública, pelos agentes do governo envolvidos no processo. Por outro lado, a desconcentração ou descongestionamento, como afirma Rivas (1991, p. 2), acontece por meio de tarefas ou de ações que são repassadas aos governos locais, não inibindo, no entanto, o poder de decisão, que continua nas mãos do governo central.

No Brasil, a descentralização da educação, em seus diferentes estágios, reflete as estratégias de avanço das políticas neoliberais, ocorridas nas últimas décadas. As políticas educacionais brasileiras, nas décadas de 1980 e 1990, foram marcadas pelos princípios da descentralização, privatização e flexibilização, ligadas aos organismos multilaterais, como o Banco Mundial, o FMI e a UNESCO, que buscavam consolidar a redução dos gastos sociais do governo com foco, sobretudo, nas garantias aos credores nacionais e estrangeiros.

A descentralização, enquanto política do Banco Mundial, ocorre no Brasil desde a década de 1990, priorizando o ensino fundamental, a privatização do ensino médio e superior, a redefinição do papel do Estado e a retirada gradativa da oferta de serviços públicos, principalmente relacionados à saúde e à educação.

Pouca importância tem sido dada ao financiamento da educação básica, por parte do governo central. Sob discurso da descentralização enquanto parte das reformas neoliberais, 
Recursos Federais para a Educação Básica

verifica-se a adoção de uma política centralizada e privatista, que visa ao controle do sistema por meio de avaliações nacionais e de currículos definidos pelo poder central e impostos aos entes federados.

A descentralização da educação pretendeu privatizar as relações sociais dentro dos sistemas educacionais e torná-las mercadorias, determinando uma maior complexidade institucional das esferas públicas e privadas na área educacional. O paradigma construído delimitou uma forma de descentralização associada à centralização, sob o esquema do modelo gerencial e por meio das avaliações e dos currículos montados no âmbito central, com acréscimos dos estados, províncias ou municípios, conforme o caso (COSTA, 2011, p. 75).

De fato, a descentralização educacional visa à redução dos recursos do fundo público com educação, por meio da política de fundos, escondendo o não cumprimento do papel redistribuidor (política redistributiva) da União, no que se refere à equidade educacional na educação básica, sobrecarregando os demais entes federativos no financiamento educacional. O princípio da descentralização, implantado no setor educacional brasileiro, ganha sentido nos dias atuais, sobretudo quando

[...] tomado na sua intrínseca relação com o ideal de privatização e de responsabilização defendidos pela fração burguesa hegemônica. Para que os governos locais assumissem a responsabilidade sobre a educação básica (mais propriamente pelo ensino fundamental), deveriam fazê-lo a partir das condições a eles impostas. Isso incluiu, principalmente, buscar ampliar o atendimento da demanda por educação com o uso mais 'racional' dos recursos. Ou seja, aumentar o número de vagas nas escolas municipais sem que houvesse um aumento do aporte financeiro por parte do governo central (LOCATELLI, 2011, p. 3).

O aumento do aporte financeiro guarda estreita relação com a expansão dos impostos, tendo em vista constituírem-se a principal fonte de recursos para a educação, além das quotas do salário-educação.

Qualquer que seja o padrão desejável de federalismo fiscal, este deve buscar ancorarse em claras definições e responsabilidades, nas atribuições destinadas a cada ente federado, o que por certo facilitaria o processo de descentralização dos programas educacionais e dos serviços públicos de um modo geral, que passariam a ser executados diretamente na esfera municipal.

\section{Divisão das Receitas Tributárias e os Recursos para a Educação Básica}

Os fluxos de recursos públicos dependem essencialmente das relações políticas que se formam, de maneira complexa, entre os entes federados, principalmente em relação à divisão das receitas tributárias e encargos públicos. Essa gama de recursos públicos está ligada às estratégias de manutenção do equilíbrio federativo, embora, na verdade, apesar dos fluxos de recursos para financiar os investimentos e serviços públicos nos entes federados, continuem mantidas as desigualdades regionais.

A carga tributária brasileira, que expressa a razão entre o volume arrecadado de tributos e o Produto Interno Bruto (PIB), ambos considerados em termos nominais, apresenta, na série temporal que compõe este estudo, cinco momentos distintos, conforme pode ser observado no Gráfico 1, a seguir: 
Gráfico 1 - Brasil: Evolução da Carga Tributária - 2003-2019

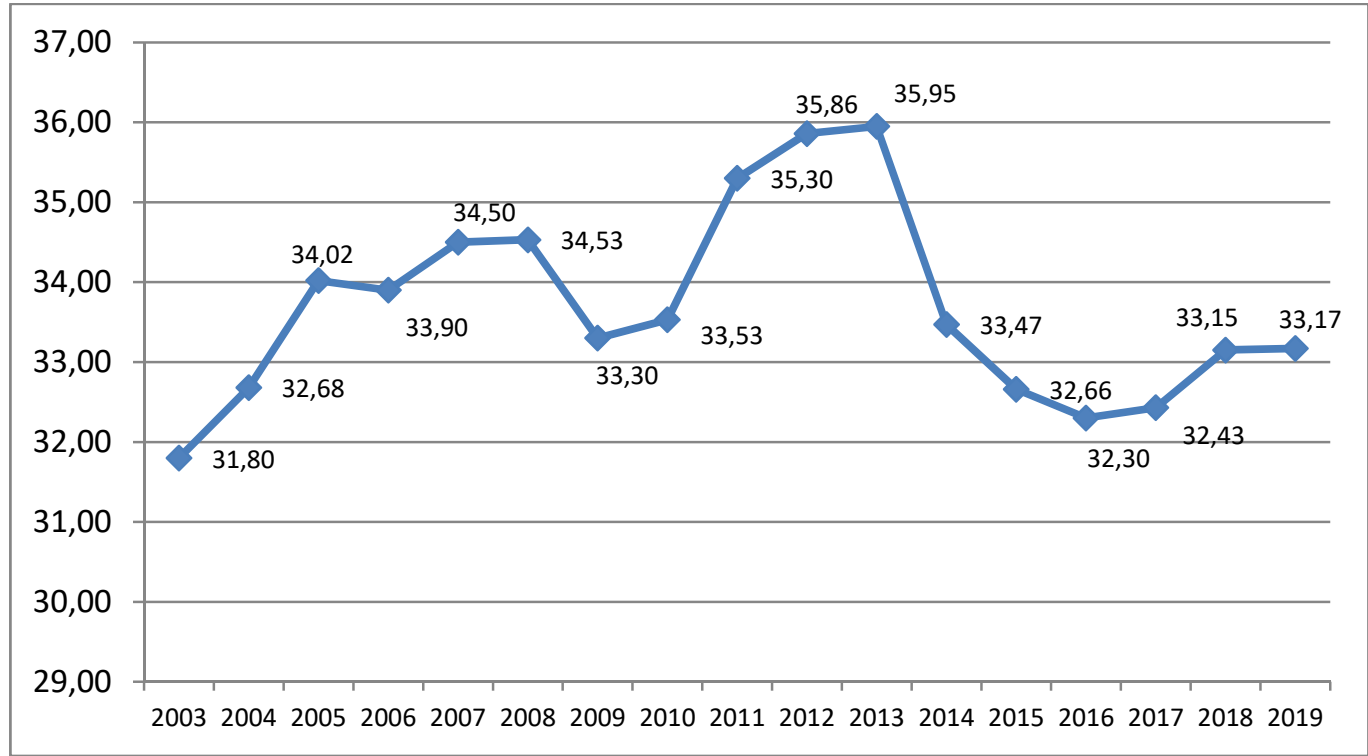

Fonte: Receita Federal Brasileira (RFB).

O primeiro momento reflete um comportamento ascendente entre os anos de 2003 a 2008, marcado pelo crescimento da economia, que, após três anos de fraco desempenho, voltou a registrar expansão.

O segundo momento apresenta um comportamento em declínio entre 2008 a 2010, dado que o valor de 2010 assemelha-se a 2004, e ainda à crise de $2008^{3}$, que influenciou o ciclo de arrecadação tributária. Essa crise, que foi deflagrada no mercado hipotecário dos EUA, contaminou a economia brasileira, em um primeiro momento, pelo enxugamento das linhas de crédito e, em um segundo momento, em meio a um cenário de grandes incertezas, os efeitos negativos repercutiram no setor real da economia, com redução do ritmo de produção.

No terceiro momento, observa-se a característica ascendente entre 2010 e 2013, momento em que a economia brasileira cresceu de forma acelerada e todos os macrossetores econômicos registraram índices crescentes.

O crescimento da atividade econômica repercutiu positivamente na arrecadação de tributos. A evidência mais clara dessa resposta está na expansão da receita tributária, principalmente em tributos como COFINS e IPI e contribuição previdenciária ao INSS.

No quarto momento (2013 a 2016), volta-se ao comportamento descendente atribuído, segundo a Assessoria Econômica do Ministério de Planejamento, Orçamento e Gestão, a uma tendência à estabilidade decorrente do fato de que, nos últimos anos, não tem havido medidas que visem a aumentar os tributos, além do fim da CPMF e da política de desonerações tributárias adotadas nos últimos anos (BRASIL, 2015, p. 8). A arrecadação total de cada ano

3 "Trata-se de uma crise financeira sendo a maior da história do capitalismo desde a grande depressão de 1929. Teve início com o colapso da bolha especulativa no mercado imobiliário nos Estados Unidos, alimentada pela expansão de crédito bancário e fortalecida pelo uso de novos instrumentos financeiros, a crise financeira se espalhou pelo mundo todo em poucos meses". Disponível em: https://www.valor.com.br/opiniao/1004628/origem-causas-eimpacto-da-crise. Acesso em: 17 ago. 2016. 
Recursos Federais para a Educação Básica

também é influenciada pelas receitas de parcelamentos, que se referem a dívidas de exercícios anteriores.

E, finalmente, no período 2016-2019, registra-se uma recuperação da economia. A carga tributária foi impulsionada, segundo o tesouro nacional, por acréscimos no Programa de Integração Social (PIS), pela Contribuição para o Financiamento da Seguridade Social (COFINS), além do Imposto de Renda e do Imposto sobre importações (BRASIL, 2018a, p. 1).

Pela ótica da participação dos entes federados na arrecadação tributária total, observase uma tendência de redução da participação da União na arrecadação total, registrando a quarta redução seguida. Por outro lado, a participação dos estados e municípios registra aumento sucessivo nos últimos anos da série, conforme o Gráfico 2, a seguir.

\section{Gráfico 2 - Evolução da participação dos entes federativos na arrecadação total de tributos - 2010-2019}

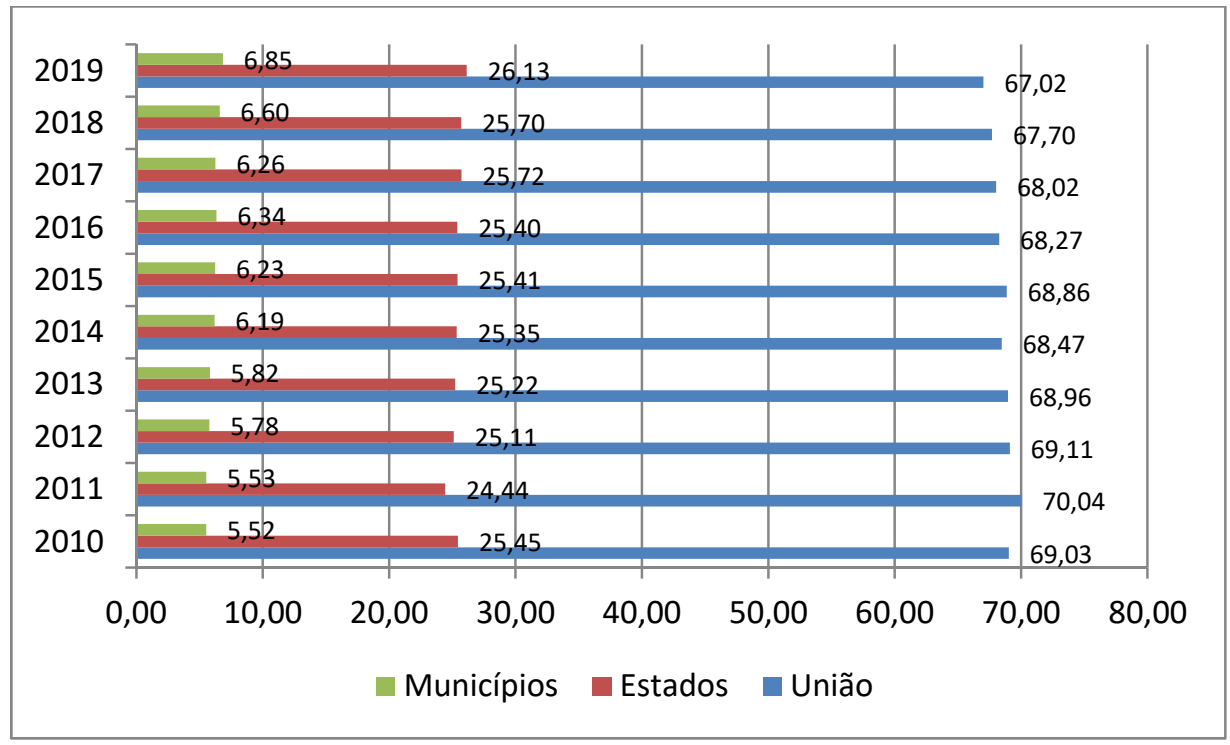

Fonte: Receita Federal Brasileira (RFB).

Registre-se, ainda, que, apesar da baixa participação municipal na arrecadação total dos tributos, é a rede municipal de ensino que possui a maior carga de responsabilidades sobre a educação infantil e o ensino fundamental quando agrega os maiores volumes de matrículas condizentes com a legislação nacional. A parca distribuição de recursos federais, cujos objetivos centram-se na diminuição das disparidades regionais, não impacta positivamente na redução da desigualdade social entre os municípios.

Pela ótica dos recursos tributários, percebemos certo abismo entre estados e municípios brasileiros, o que indica que a divisão de responsabilidades na oferta da educação básica não é uniforme.

$\mathrm{Na}$ mensuração do tamanho da matrícula, nesse nível de ensino, por dependência administrativa (Tabela 1), percebe-se que a rede municipal de ensino é responsável pelo maior quantitativo de matrículas, representando em 2018 cerca de $48 \%$ do total de matrículas no Brasil. 
Recursos Federais para a Educação Básica

Tabela 1 - Brasil: Número de Matrículas de Educação Básica, por Dependência Administrativa - 2005/2007/2009/2015/2017

\begin{tabular}{c|c|c|c|c|c|c|c|c|c}
\hline Ano & Total & Federal & $\%$ & Estadual & $\%$ & Municipal & $\%$ & Privada & $\%$ \\
\hline 2005 & 56.471 .622 & 182.499 & 0,3 & 23.571 .777 & 42 & 25.286 .243 & 45 & 7.431 .103 & 13 \\
\hline 2007 & 53.028 .928 & 185.095 & 0,3 & 21.927 .300 & 41 & 24.531 .011 & 46 & 6.385 .522 & 12 \\
\hline 2009 & 52.580 .452 & 217.738 & 0,4 & 20.737 .663 & 39 & 24.315 .309 & 46 & 7.309 .742 & 14 \\
\hline 2015 & 48.796 .512 & 376.230 & 0,8 & 16.548 .708 & 34 & 22.813 .842 & 47 & 9.057 .732 & 19 \\
\hline 2017 & 48.608 .093 & 396.482 & 0,8 & 16.222 .814 & 33 & 23.101 .736 & 47 & 8.887 .061 & 18 \\
\hline 2018 & 48.455 .867 & 411.078 & 0,8 & 15.946 .416 & 33 & 23.103 .124 & 48 & 8.995 .249 & 18 \\
\hline $2018 / 2005(\%)$ & -14 & 125 & & -32 & & -9 & & 21 & \\
\hline
\end{tabular}

Fonte: MEC/INEP $(2005,2007,2009,2015,2017)$.

No período em análise, observa-se que o número de matrículas na educação básica, no Brasil, vem diminuindo ao longo do tempo. Entre 2005 e 2018, essa redução atinge a taxa de $-14 \%$, representando uma redução absoluta de 8.015 .755 alunos. Declínio expressivo potencializado pelas quedas registradas nas dependências estadual $(-32 \%)$ e municipal $(-9 \%)$ de ensino. Por outro lado, a rede privada absorveu mais de 1,5 milhões de alunos, crescendo em torno de $21 \%$ no período.

É importante, na busca de um cenário equitativo, comparar o quadro da distribuição da oferta de matrículas na educação básica com a distribuição da carga tributária do país e do gasto público em educação. Em 2017, a distribuição da carga tributária utilizada estava assim constituída: $68,02 \%$ para a União, $25,72 \%$ para os estados e $6,26 \%$ para os municípios (BRASIL, 2018b, p. 3). Nota-se, portanto, que essa distribuição tributária é completamente inversa às proporcionalidades da matrícula na educação básica nas esferas públicas, o que deixa claro que a divisão dos recursos para o financiamento da educação básica ainda é uma questão latente no bojo do federalismo fiscal.

A prioridade conferida à distribuição dos recursos elege as áreas mais carentes, ao mesmo tempo que cria um coeficiente de distribuição dos recursos do salário-educação, de acordo com o número de alunos matriculados no ensino fundamental, com base no censo escolar do ano anterior (formas de assistência financeira direta e automática do Fundo Nacional de Desenvolvimento da Educação - FNDE). O confronto dessas prioridades infere ato contraditório, pois o maior volume de alunado não reflete necessariamente o espaço territorial mais carente de cuidados socioeconômicos e educacionais. Além disso, os coeficientes de distribuição são flutuantes no tempo, isto é, por dependerem do tamanho de matrículas no ano, podem sofrer decréscimos ou acréscimo (neste caso muito incipiente), o que impacta diretamente no volume de recursos destinados aos estados e municípios provenientes dos programas geridos pelo FNDE.

Os programas de descentralização de recursos financeiros esbarram em limitações próprias das desigualdades sociais presentes na sociedade brasileira. Os fins dessa política não visam superar as barreiras históricas da desigualdade na distribuição dos recursos financeiros na educação básica, pois ela se assenta nas contradições do modo de produção capitalista, e, como tal, visa, contraditoriamente, à manutenção e reprodução social.

Sob a ótica das políticas públicas educacionais, é visível a manifestação dos municípios brasileiros na busca constante por recursos para a educação básica, por meio de convênios, 
Recursos Federais para a Educação Básica

adesão a programas e projetos educacionais, e sua subordinação ao Plano de Ações Articuladas (PAR) e outras transferências automáticas por parte do MEC/FNDE.

A comparação estabelecida entre os recursos próprios do município, oriundos dos $25 \%$ dos impostos e aqueles com origem no FNDE, contidos na Tabela a seguir, mostra que a educação pública municipal ainda está dependente dos seus próprios recursos e que os recursos transferidos pelo FNDE (recursos federais), embora complementares, são proporcionalmente menores, tanto em 2003 quanto em 2016. O que denota que, embora as distâncias proporcionais tenham diminuído, é o município que, com participação tributária menor, arca com maiores recursos para a educação básica local.

Tabela 2 - Comparativo entre os $25 \%$ de impostos próprios do município e os recursos transferidos pelo FNDE - 2003/2016

\begin{tabular}{lcccc}
\hline \multicolumn{1}{c}{ Itens } & $\mathbf{2 0 0 3}$ & $\mathbf{\%}$ & $\mathbf{2 0 1 6}$ & \% \\
\hline $25 \%$ de impostos Próprios & $11.304 .828 .091,40$ & 87,13 & $50.901 .993 .633,77$ & 72,14 \\
$\begin{array}{l}\text { Recursos Transferidos pelo } \\
\text { FNDE }\end{array}$ & $1.670 .258 .465,55$ & 12,87 & $19.658 .179 .558,81$ & 27,86 \\
Total & $\mathbf{1 2 . 9 7 5 . 0 8 6 . 5 5 6 , 9 5}$ & $\mathbf{1 0 0 , 0 0}$ & $\mathbf{7 0 . 5 6 0 . 1 7 3 . 1 9 2 , 5 8}$ & $\mathbf{1 0 0 , 0 0}$ \\
\hline
\end{tabular}

Fonte: STN/FINBRA, 2003/2016.

Os recursos transferidos pelo FNDE, embora crescentes em 2016, são ainda pouco representativos na estrutura de gastos com educação nos municípios brasileiros. É possível observar que, apesar da baixa participação desses recursos, verifica-se uma maior similaridade entre os repasses efetivados, sobretudo para os estados das Regiões Nordeste e Centro-Oeste. O que se nota também, por meio dos dados, é que os recursos oriundos do FNDE, especificamente para a esfera municipal (Gráfico 3), ainda possuem um comportamento senoidal (alternância de comportamento), entre os municípios das unidades federadas brasileiras, balizado no critério de transferência, que alega que os recursos devem ser direcionados às áreas mais carentes de incentivo financeiro. Nesse sentido, segundo os dados, esses recursos já foram maiores em estados como Pará, Maranhão, Ceará e Alagoas (2003), portanto, centrados nas Regiões Norte e Nordeste, e agora se mostram mais representativos em estados como Rio de Janeiro, Santa Catarina, São Paulo e Rio Grande do Sul, portanto, estados das Regiões Sudeste e Sul (2016), mostrando possível viés nos critérios utilizados na distribuição dos recursos para a educação básica municipal, o que contradiz os critérios de transferência utilizados quanto ao atendimento de áreas mais carentes. 
Recursos Federais para a Educação Básica

\section{Gráfico 3 - Participação dos recursos do FNDE na esfera municipal, segundo unidades da federação - 2003/2016 (\%)}

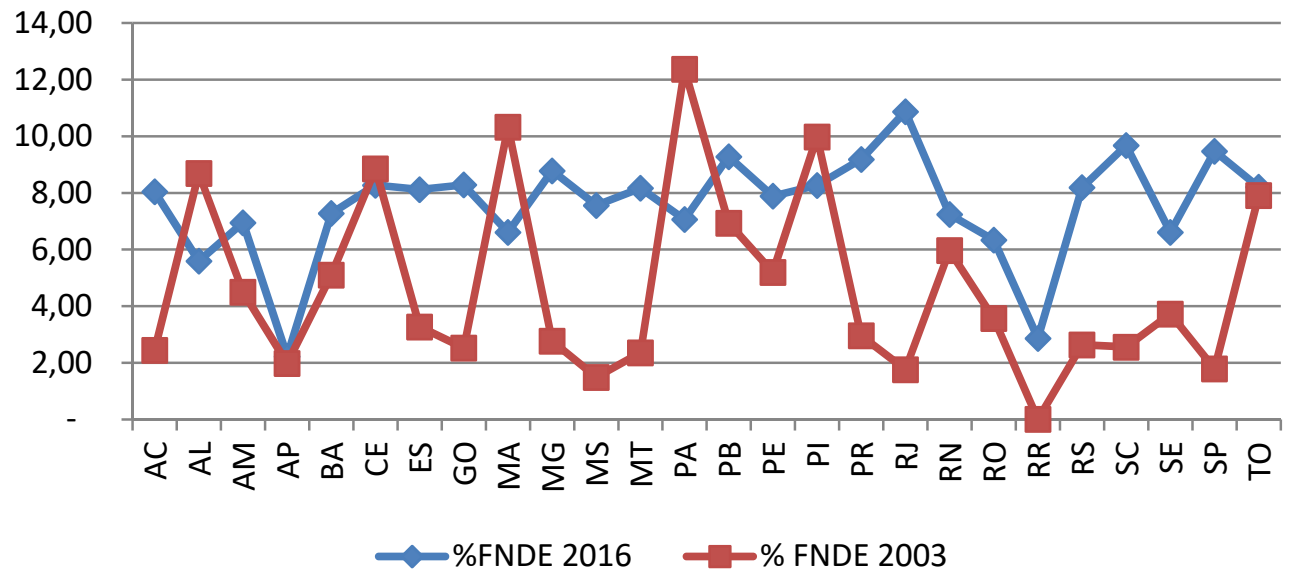

Fonte: FINBRA 2003/16.

Advém do texto constitucional que as oportunidades de acesso à escola são iguais para todos. No entanto, a qualidade do ensino que se objetiva alcançar com a assistência técnica e financeira da União é mínima. Sob essa ótica, o governo central não intenciona grandes modificações no quadro educacional brasileiro, pois sua assistência financeira mantém o mínimo controlado, e assim atende aos preceitos neoliberais de concorrência mercadológica em que a escola precisa deixar de ser pública, caminhar com seu próprio peso e problemas, disputando seu espaço no mercado educacional.

Não se pode responsabilizar, no entanto, a União por políticas que cabem também aos demais entes federados, como prevê o art. 212 da CF/88. Existem responsabilidades, sejam materiais ou financeiras, que cabem aos demais entes federados para o financiamento da educação. Portanto, o que se abate hoje sobre a educação escolar, "[...] realidade intolerável de indicadores sociais reveladores de privação social, realidade quase que tornada uma situação imutável" (CURY, 2010, p. 162), não tem a total responsabilidade da União. Estados e municípios também congregam do mesmo regime federalista e, portanto, efetivam a sua coparticipação em tal situação.

No atual regime federalista brasileiro há a distribuição de competências, sejam elas legislativas, normativas ou financeiras, o que resulta na forma de atuação de cada ente federado e no elo de articulação comum a todos.

\footnotetext{
Trata-se, pois, de um regime em que os poderes de governo são repartidos entre instancias governamentais por meio de campos de competências legalmente definidas. [...] O federalismo de cooperação busca um equilíbrio de poderes entre a união e os estados-membros, estabelecendo laços de cooperação na distribuição das múltiplas competências por meio de atividades planejadas e articuladas entre si, objetivando fins comuns. Esse federalismo político e cooperativo é o registro jurídico forte de nossa atual constituição (CURY, 2010, p. 152).
}

A CF/88 admite ser o Brasil uma república federativa com união indissolúvel dos estados, municípios e do Distrito Federal (art. $1^{\circ} \mathrm{CF} / 88$ ). Essa estrutura está ligada ao princípio da cooperação recíproca, conforme artigos $1^{\circ}, 18,23$ e $60, \S 4^{\circ}$, inciso I. Percebese, assim, como a CF/88 reparte as competências entre seus membros federados, 
reconhecendo, inclusive, os municípios como membro. O elo entre os entes federados pressupõe a cooperação ou colaboração recíproca, isto é, um regime de colaboração.

O regime de colaboração, seja em termos de conteúdo, seja em termos de mecanismos, é difícil, lento e necessariamente negociado. [...] Esse regime de colaboração recíproca supõe normas e finalidades gerais, por meio de competências privativas, concorrentes e comuns. Contudo, sem um regime fiscal e financeiro que atenda de fato ao pacto federativo, o alcance das políticas torna-se minimizado (CURY, 2010, p. 160).

A marginalização municipal, sobretudo na participação de decisões importantes da educação, não condiz com a realidade do pacto. Sabe-se que os recursos municipais próprios não são suficientes para arcar com as responsabilidades sobre a educação infantil e o ensino fundamental impostas pelo pacto federativo. Os recursos do FUNDEB ${ }^{4}$ também são insuficientes e dependem sobremaneira dos recursos municipais e estaduais oriundos dos impostos vinculados. Se a CF/88 fosse devidamente cumprida nesses 30 anos,

[...] a conjuntura educacional do Brasil seria bem diferente. Entretanto, isso não ocorre porque, embora as diretrizes da educação nacional tenham sido amplamente delineadas, especialmente após a aprovação da Lei de Diretrizes e Bases da Educação Nacional (LDB), as bases, ou seja, as condições materiais que podem viabilizar a implementação do direito à educação ainda são muito genericamente definidas, principalmente frente à insuficiência de recursos para universalizar e qualificar a oferta educacional pública (CRUZ, 2012, p. 82).

Ainda, segundo a autora, embora de fundamental importância, a atual vinculação constitucional de recursos, visando à manutenção e desenvolvimento do ensino (MDE), ainda é incipiente para os objetivos que visam garantir que o setor educacional obtenha recursos necessários para uma oferta educacional qualificada.

Além desse problema, existe também uma tendência de descontinuidade das políticas educacionais. Para Saviani (2014), esse é um complicador político para a formação de um sistema nacional de educação, pois retrata um processo fragmentado, imposto por reformas educacionais, cujo objetivo está muito mais para a protelação do que para a real preocupação com o desenvolvimento da educação. Já faz algum tempo que se fala da erradicação do analfabetismo e na redução do déficit de aprendizagem, sem que medidas concretas sejam devidamente implementadas para os objetivos pretendidos. O que se vê, comumente, como informa Saviani (2014, p. 36), é um movimento zig-zag que "[...] indica o sentido tortuoso, sinuoso das variações e alterações sucessivas observadas nas reformas". Essas variações podem ser vistas no adiamento frequente de medidas que visem a eliminação do analfabetismo e dos críticos problemas vinculados à qualidade do ensino. Para enfrentar esses problemas, diz o autor que

4 O Fundo de Manutenção e Desenvolvimento da Educação Básica e de Valorização dos Profissionais da Educação (FUNDEB) é um fundo especial, de natureza contábil e de âmbito estadual (um fundo por estado e Distrito Federal, num total de vinte e sete fundos), formado, na quase totalidade, por recursos provenientes dos impostos e transferências dos estados, Distrito Federal e municípios, vinculados à educação por força do disposto no art. 212 da Constituição Federal. Além desses recursos, ainda compõe o Fundeb, a título de complementação, uma parcela de recursos federais, sempre que, no âmbito de cada estado, seu valor por aluno não alcançar o mínimo definido nacionalmente. Independentemente da origem, todo o recurso gerado é redistribuído para aplicação exclusiva na educação básica. Entrou em vigor em janeiro de 2007 e se estenderá até 2020, conforme prevê a Emenda Constitucional $n^{\circ} 53$, que alertou o Art. 60 do Ato de Disposições Constitucionais Transitórias (ADCT). Disponível em: https://www.fnde.gov.br/financiamento/fundeb. Acesso em: 06 jun. 2019. 
Recursos Federais para a Educação Básica

A Constituição de 1988 fixou o prazo de dez anos para o cumprimento dessa meta: 1998. O Plano Decenal 'Educação para Todos', de 1993, também 10 anos: 2003. O FUNDEF, de 1996, igualmente 10 anos: 2006. O PNE de 2001, também 10 anos: 2011. O FUNDEB de 2006, 14 anos: 2020. O PDE de 2007, 15 anos: 2022 (SAVIANI, 2014, p. 36-37).

Todo esse descaso com a educação básica nacional resulta, na visão do autor, em precarização geral da educação em todo o País, seja na sua rede física, nos equipamentos, nas condições mínimas de trabalho e o salário dos docentes, além de fragilidades teóricas pedagógicas de ensino e aprendizagem, nos currículos e na avaliação de resultados. A despeito desse quadro, o financiamento da educação básica não surte efeitos positivos e as desigualdades se perpetuam.

\section{Considerações Finais}

O marco que se coloca como indutor de melhorias na educação básica nacional, partindo do pressuposto de que imperam nas escolas brasileiras a incapacidade de gerir melhores dias para a educação, está na afirmação neoliberal de que o Estado é inoperante, refletindo negativamente na escola, que é incapaz de formar um "produto" de melhor qualidade. A ideia não perpassa enquanto ação que venha a ser disseminada, visando atingir a classe menos favorecida, mas investe-se num olhar meramente capitalista, cujo foco principal é o lucro.

O Estado brasileiro, sendo neoliberal, mostra-se contraditório, pois, ao mesmo tempo que sustenta constitucionalmente as necessárias funções redistributiva e supletiva, no tocante à assistência técnica e financeira aos entes federados, opõe-se a essa intervenção, como participante de uma política que induz à desigualdade, facilitando o seu próprio desenvolvimento.

A expansão das matrículas, por seu turno, não garantiu a eficiência, a eficácia e a produtividade tão esperadas pelos neoliberais. Garantiu, sim, uma distribuição desigual na oferta dos serviços educacionais. Faltam recursos humanos e financeiros, mas é atribuída ao Estado a responsabilidade, sobre acusação de que é ineficiente na gestão das políticas públicas educacionais. Por conta disso, foram feitas reformas educacionais a partir da década de 1990, implementadas em vários países do mundo, repercutindo prioritariamente na periferia do capital, a exemplo da frágil democracia brasileira.

O processo de descentralização, cujo objetivo residia no completo aniquilamento do Estado enquanto gestor da educação, não se deu de forma completa. Ainda se centralizam as decisões mais importantes do cenário educacional.

A municipalização, por seu turno, vista como um processo de descentralização dos serviços educacionais, não aconteceu completamente e acabou por se transformar em um processo de "prefeiturização" (SOUZA; FARIA, 2004), deixando aos municípios, com seus parcos recursos, a árdua tarefa de desenvolver a educação básica, eliminando os focos de desigualdades educacionais com a colaboração ínfima do governo central. Os recursos financeiros não são suficientes, e nunca serão, sem que haja uma completa reforma tributária que de fato aumente a participação dos impostos direcionados à educação brasileira.

A regra geral neoliberal é que somente o mercado tem o direito de alocar eficientemente os recursos e fixar os níveis de renda. Esforços que não se coadunem com esse direito quase sempre serão deixados à margem. Não se descarta, todavia, a participação da sociedade civil 
Recursos Federais para a Educação Básica

nas lutas pela educação, traduzida em conquistas importantes no cenário educacional brasileiro a exemplo do FUNDEB, PNLD e PNAE.

Além disso, esperar que as políticas públicas educacionais sejam capazes de promover a igualdade social é pura ingenuidade, dado que a desigualdade e a exclusão social são inerentes à democracia burguesa e ao modo de produção capitalista. Igualdade, nesse sentido, não passa de uma falsa esperança, de um discurso ideológico somente possível em outra forma de Estado, cujos objetivos sociais focalizassem de fato os reais interesses das classes sociais menos favorecidas, o cidadão de fato e de direito.

Quando olhamos a tese básica de Hayek (1983), que diz ser a desigualdade fundamental para a eficiência e produtividade capitalista, o que infelizmente vem acontecendo no Brasil, inferimos que, segundo essa tese, as possibilidades de alcance de direitos igualitários não existem.

Tanto a CF/88 quanto a LDB expressam claramente as devidas partilhas de responsabilidades entre as esferas subnacionais. Todavia, sendo o Brasil um dos países mais desiguais do mundo, apresenta certas fragilidades no seu regime federativo, uma vez que existem diferenças substanciais na distribuição das receitas fiscais, na forma como as políticas são implantadas e na forma como são repassados os recursos.

Por outro lado, o impasse da desigualdade educacional não será resolvido somente com aportes financeiros. O modo de atuação do poder público, aliado às questões de cunho federativo, são obstáculos à matéria, pois criam verdadeiros desníveis socioeconômicos e educacionais entre as regiões brasileiras. Persistem as desigualdades econômicas e sociais com reflexo último nos territórios subnacionais. Reflexo esse que é marcado pela tendência à descentralização e da transferência das responsabilidades do ensino aos estados e municípios.

A União, enquanto agente redutor das desigualdades educacionais, não o faz e não o fará, deixando que os estados e municípios assumam suas responsabilidades pelo atendimento educacional, atendimento esse que recebe contornos diferenciados nos estados do Sul e Sudeste, bem como nos estados do Norte e Nordeste.

Essas diferenças são decorrentes, principalmente, da estrutura tributária vigente. Aqueles estados mais ricos se ocupam diretamente de suas responsabilidades perante a oferta educacional. Os estados menos providos de recursos desincumbiram-se dessa tarefa, ponderando seus limites e possibilidades. Todavia, a disponibilidade dos recursos financeiros é de suma importância para os governos locais, principalmente pela possibilidade de redução das influências exercidas pelo governo central, que usa do pretexto da descentralização enquanto instrumento ideológico para mascarar sua própria assistência financeira, quando na verdade utiliza-se da desconcentração, não permitindo o poder de decisão aos governos locais quanto à implementação de programas educacionais, muita das vezes completamente díspares da real necessidade local.

Os aspectos políticos interferem diretamente nessa questão, pois a descentralização ocorre de acordo com os interesses políticos. Existe a falsa ilusão de que o governo realmente se interessa em resolver os problemas sociais, sobretudo aqueles relacionados à desigualdade educacional. O governo controla a tomada de decisão e não abre mão desse poder, portanto, desconcentra tarefas e ações, mantendo-se no centro do controle e deixando à míngua as autonomias subnacionais, ferindo assim o pacto federativo. 
Recursos Federais para a Educação Básica

Aludir que a descentralização, isto é, que as unidades descentralizadas estão mais próximas da escola e seus beneficiários e, assim, dispõem de informações mais precisas e recentes, é uma forma de controle e falácia neoliberal, sobretudo quando se considera a importância dos conselhos escolares na superação dos interesses centrais.

A redução dos gastos públicos via descentralização esconde o fato do não cumprimento do papel redistribuidor da União, sobrecarregando os demais entes federados, que devem racionar seus recursos, aumentar o número de matrículas nas escolas, sobretudo municipais, sem o devido aumento do aporte financeiro.

No Brasil, existe a partilha federativa da receita tributária, seja ela própria ou transferível. As transferências consideram geralmente as assimetrias sociais cuja intervenção política as condiciona, por isso, preservar a federação no Brasil será sempre um produto de um pacto político. Essa é a fragilidade do federalismo brasileiro, sua existência está condicionada ao mercado e a um pacto político, que não são capazes de garantir uma aliança federativa duradoura.

Todas as ações e políticas sociais estão condicionadas à existência de recursos financeiros e os fluxos dos recursos públicos dependem significativamente das relações políticas entre os entes federados, relações essas que guardam certa complexidade advinda, sobretudo, da divisão das receitas tributárias e encargos públicos.

A qualidade do ensino que se almeja alcançar com a assistência técnica e financeira é mínima, o governo central não programa grandes modificações no quadro educacional brasileiro que impacte significativamente na redução das desigualdades educacionais atuais. Sua assistência mínima não permite esse alcance. É a manutenção do mínimo, o fazer o mínimo, atendendo aos preceitos neoliberais de concorrência mercadológica.

O regime de assistência financeira e técnica, constante da pauta de ações do FNDE, abarca na sua implementação um modelo de gestão influenciado pelo mecanicismo mercadológico, trazendo, para a esfera das relações entre os entes federados, certos controles, tanto nos momentos iniciais do repasse financeiro, quanto no monitoramento da aplicação dos recursos e na sua prestação de contas. A viabilização da política de financiamento dos programas educacionais do FNDE não descarta medidas de controle na concretização dos seus objetivos.

\section{Referências}

AZEVEDO, Janete Maria Lins. A educação como política pública. 3. ed. Campinas: Autores Associados, 2004.

BRASIL. Constituição de 1988. Constituição da República Federativa do Brasil. Diário Oficial da União, Brasília, 5 out. 1988.

BRASIL. Ministério da Educação. Módulo competências básicas. Fundo Nacional de Desenvolvimento da Educação. Brasília: MEC; FNDE; SEED, 2006.

BRASIL. Tesouro Nacional, Estimativa da carga tributária bruta no Brasil, Ministério da Fazenda, Brasília, 2018a. 
Recursos Federais para a Educação Básica

BRASIL. Receita Federal, Carga Tributária no Brasil, Análise por tributos e bases de incidências, CETAD - Centro de estudos tributários e aduaneiros, Ministério da Fazenda, Brasília, nov. 2018b.

COSTA, Fábio Luciano Oliveira. As reformas educacionais na América Latina na década de 1990. Ver a Educação, v. 12, n. 1, p. 65-68, jan./jun. 2011.

CRUZ, Rosana Evangelista da. Os recursos federais para o financiamento da educação básica. Revista de financiamento da educação FINEDUCA, v. 2, n. 7, 2012.

CURY, Carlos Roberto Jamil. Educação e crise: Perspectiva para o Brasil. Educação \& Sociedade, Campinas, v. 31, n. 113, out./dez. 2010.

FRIGOTTO, Gaudêncio. Educação e a crise do capitalismo real. 6 . ed. São Paulo: Cortez, 2010.

GENTILI, Pablo. Neoliberalismo e Educação: manual do usuário. In: SILVA, Tomaz Tadeu da; GENTILI, Pablo. Escola SIA: quem ganha e quem perde no mercado educacional do neoliberalismo. Brasília: CNTE, 1996.

HAYEK, Friedrich August Von. Os fundamentos da liberdade. São Paulo: Visão, 1983.

LOCATELLI, Cleomar. A política de descentralização na educação brasileira: resultados e consequências. In: JORNADA INTERNACIONAL DE POLÍTICAS PÚBLICAS - JOINPP, 5., 2011, UFMA. Anais... 2011.

MÉSZÁROS, István. Para além do capital: rumo a uma teoria da transição. Tradução de Paulo Cezar Castanheira, Sérgio Lessa. São Paulo: Boitempo, 2011.

RIVAS, R. H. Política de Descentralização em la educación básica y média em América Latina: estado del arte. Santiago: UNESCO/REDUC, 1991.

SAVIANI, Demerval. Sistema Nacional de Educação e Plano Nacional de Educação: significado, controvérsias e perspectivas. Campinas: Autores Associados, 2014.

SILVA, Maria Abadia da. A hegemonia do Banco Mundial na formulação e no gerenciamento das políticas educacionais. Revista Nuances: Estudo sobre educação, São Paulo, UNESP, v. $6,2000$.

SOUZA, Donaldo Bello de; FARIA Lia Ciomar Macedo de. Políticas de financiamento da educação municipal do Brasil (1996-2002): das disposições legais equalizadoras às políticas políticos-institucionais excludentes. Ensaio: Avaliação e Políticas públicas em educação, Rio de Janeiro, v. 12, n. 42, p. 564-582, jan./mar. 2004. 
Recursos Federais para a Educação Básica

Antônio Cláudio Andrade dos Reis é doutor em Educação na linha de Políticas Públicas Educacionais pelo Programa de Pós-Graduação em Educação do Instituto de Ciências da Educação ICED/UFPA (2019); mestre em economia regional na área de concentração Desenvolvimento Econômico Regional pelo Programa de Pós-Graduação em Economia do Instituto de Ciências Sociais Aplicadas ICSA/UFPA (2012). Atualmente é Professor do Magistério Superior junto ao Instituto de Ciências da Educação - ICED da Universidade Federal do Pará - UFPA.

ORCID: http://orcid.org/0000-0003-1305-9469

E-mail: aclaudioreis@yahoo.com.br

Vera Lúcia Jacob Chaves possui graduação em Pedagogia pela Universidade Federal do Pará (1989), graduação em Ciências Sociais pela Universidade Federal do Pará (1977), Mestrado em Educação e Políticas Públicas pela Universidade Federal do Pará (1996) e doutorado em Educação-Conhecimento e Inclusão Social (Nota 7) pela Universidade Federal de Minas Gerais (2005), com Pós-Doutorado no Instituto de Educação da Universidade de Lisboa e Pós-Doutorado no Programa de Políticas Públicas e Formação Humana da UERJ. Atualmente é professora Titular aposentada da UFPA e orienta em nível de Mestrado e Doutorado.

ORCID: http://orcid.org/0000-0003-3128-3659

E-mail: veraluciajacob@gmail.com 


\section{Editores do volume 11}

Márcia Aparecida Jacomini - Universidade Federal de São Paulo, Brasil

José Marcelino de Rezende Pinto - Universidade de São Paulo, Brasil

\section{Comitê Editorial}

Nalú Farenzena - Universidade Federal do Rio Grande do Sul, Brasil

Juca Gil - Universidade Federal do Rio Grande do Sul, Brasil

Theresa Adrião - Universidade Estadual de Campinas, Brasil

Ângelo Ricardo de Souza - Universidade Federal do Paraná, Brasil

\section{Conselho Editorial}

\section{Alejandro Morduchowicz}

Universidad Pedagógica, Provincia de Buenos Aires, Argentina

Andréa Barbosa Gouveia

Universidade Federal do Paraná, Brasil

Fernanda Saforcada

Universidade de Buenos Aires, Argentina

Jacques Velloso

Universidade de Brasília, Brasil

João Monlevade

Senado Federal, Brasil

Jorge Abrahão de Castro

Instituto de Pesquisa Econômica Aplicada / IPEA, Brasil

Lisete Regina Gomes Arelaro

Universidade de São Paulo, Brasil

Luis Carlos Sales

Universidade Federal do Piauí, Brasil

Luiz de Sousa Junior

Universidade Federal da Paraíba, Brasil

Luiz Fernandes Dourado

Universidade Federal de Goiás, Brasil

Magna França

Universidade Federal do Rio Grande do Norte, Brasil

Marcos Edgar Bassi

Universidade Federal de Santa Catarina, Brasil

Maria Angélica Pedra Minhoto

Universidade Federal de São Paulo, Brasil

Maria Beatriz Luce

Universidade Federal do Rio Grande do Sul, Brasil

Maria Dilnéia Espíndola Fernandes

Universidade Federal de Mato Grosso do Sul, Brasil

Nelson Cardoso do Amaral

Universidade Federal de Goiás, Brasil

Nicholas Davies

Universidade Federal Fluminense, Brasil

Robert E. Verhine

Universidade Federal da Bahia, Brasil

Romualdo Portela de Oliveira

Universidade de São Paulo, Brasil

Rosana Gemaque Rolim

Universidade Federal do Pará, Brasil

Rubens Barbosa de Camargo

Universidade de São Paulo, Brasil

Theresa Adrião

Universidade Estadual de Campinas, Brasil

Tristan McCowan

University of London, Reino Unido

Vera Jacob

Universidade Federal do Pará, Brasil

Vera Peroni

Universidade Federal do Rio Grande do Sul, Brasil

Vitor Henrique Paro

Universidade de São Paulo, Brasil

\section{Equipe editorial}

Apoio ao Comitê Editorial: Caio Cabral da Silva

Diagramação, Revisão de português e normalização: Edson Leonel de Oliveira

Revisão de inglês: Sabrina Ferreira

Fineduca - Revista de Financiamento da Educação

Associação Nacional de Pesquisa em

Financiamento da Educação

e-mail: revista.fineduca@gmail.com | site: http://seer.ufrgs.br/fineduca 